\title{
The similarity and diversity of semantic relations
}

\author{
ROGER CHAFFIN \\ Trenton State College, Trenton, New Jersey \\ and \\ DOUGLAS J. HERRMANN \\ Hamilton College, Clinton, New York
}

\begin{abstract}
There is a rich variety of semantic relations in natural languages. Subjects' perceptions of similarities among relations were studied for a wider variety of relations than had been used in previous studies. Forty subjects sorted 31 cards bearing five example pairs of each of 31 semantic relations. Subjects were able both to distinguish the relations and to perceive their similarities. A hierarchical clustering analysis of the sorting data indicated that the subjects perceived five families of semantic relations (contrasts, class inclusion, similars, case relations, and part-wholes). The five families were distinguished in terms of three properties of semantic relations: contrasting/noncontrasting, logical/pragmatic, and inclusion/noninclusion. Within each family, relations also were sorted in ways consistent with their defining properties. Relations were therefore viewed not as unanalyzable primitives, but in terms of the relational properties that distinguished them.
\end{abstract}

Semantic relations between concepts are basic components of language and thought (Bierwisch, 1970; H. H. Clark, 1970; Evanechko \& Maguire, 1972; Evens, Litowitz, Markowitz, Smith, \& Werner, 1980; Katz, 1972; Leech, 1974; Miller, 1969; Miller \& JohnsonLaird, 1976; Osgood \& Richards, 1973; Palermo, 1978). Relying on associative and introspective data, Wundt (1893) identified and classified a wide range of relations. Wundt recognized two general classes: outer associations (part-wholes, word sequences) and inner associations (categorical relationships, similars, coordination, causal relations). At least 13 other classification systems were proposed prior to 1911 (Warren, 1921).

More recently, researchers have been directly concerned with the study of semantic relations in two related areas: the development of general models of semantic memory (Anderson, 1976; Norman \& Rumelhart, 1975; Schank, 1973) and the study of semantic decisions (Cohen, 1977; Danks \& Glucksberg, 1980; Kintsch, 1980; Smith, 1977). In both areas, research has focused on a limited number of relations, and the similarities between relationships have not been explored. General models of semantic memory have been developed to account for the comprehension and representation of propositional knowledge (Anderson, 1976; Norman \& Rumelhart, 1975; Schank, 1973). In these models, information is represented by a network of labeled rela.

Preparation of this article was supported in part by a faculty research grant from Trenton State College to the first author. We thank Mary Crawford for comments on an earlier version of this paper. Requests for reprints should be sent to Roger Chaffin, Department of Psychology, Trenton State College, Trenton, NJ 08625. tions between nodes that stand for concepts. Relations serve as unanalyzed, primitive terms; consequently, their number has been restricted in the interest of economy. As a result, only a fraction of the total number of relations in the English language have been considered. The scope and power of current models would be enhanced by encompassing the wider range of relations considered by earlier generations of psychologists.

Semantic decision tasks have been used primarily to explore hypotheses about the processes involved in the perception of relations between concepts. In a typical experiment, subjects are timed as they decide whether or not two words exemplify a particular target relation (e.g., Is a "robin" a "bird"?). These studies have also been limited to a few relations, primarily class inclusion (Collins \& Quillian, 1969; Loftus, 1973; McCloskey \& Glucksberg, 1979; Smith, Shoben, \& Rips, 1974), although some attention has been given to synonymity and antonymy (Glass, Holyoak, \& Kiger, 1979; Herrmann, Chaffin, Conti, Peters, \& Robbins, 1979) and to the part-whole relation (Chaffin, Herrmann, \& Andrews, 1981; Chaffin, Williams, \& Herrmann, 1982; Lorch, 1981).

The variety of relations is important both to general models of comprehension and to semantic decision models. For general models of comprehension, the differences among relations are important because relations differ in their logical properties and in the inferences that they permit. For example, contrary ("sweet-sour") and contradictory ("married-unmarried") opposition differ in that contrary opposition admits of degrees, for example, "very sweet," whereas contradictory opposition does not, for example, "very married." 
For decision models (e.g., Kintsch, 1980; Smith, 1977), the differences among relations are important because each relation might be expected to call into play a unique set of decision criteria (Herrmann et al., 1979). For example, class inclusion decisions, it has been suggested, are based on criteria for inclusion (e.g., McCloskey \& Glucksberg, 1979; Smith et al., 1974), whereas antonym decisions require an evaluation of the nature of the opposition (Herrmann et al., 1979; Herrmann, Chaffin, Daniel, \& Russo, 1981).

Once the diversity of relations is noted, it is apparent that relations vary in their similarity to each other. For example, there appears to be a family of contrast relations that have more in common with each other than they do with other relations (e.g., contradictories, "alive-dead"; contraries, "hot-cold"; directionals, "abovebelow"; reverses, "buy-sell"; incompatibles, "frankhypocritical"; see Bolinger \& Sears, 1981, Groves, 1973, and Kempsen, 1977). These family resemblances must be accounted for by models of semantic memory. Relation similarity has been found to affect performance in semantic decision tasks (Chaffin, Herrmann, \& Andrews, 1981; Chaffin, Russo, \& Hermann, 1981; Chaffin, Williams, \& Herrmann, 1981; Herrmann et al., 1979), restricted association tasks (Perfetti, 1967; Riegel \& Riegel, 1963), and ratings of conformity to a target relation (Chaffin \& Herrmann, 1981). The purpose of the present research was to develop an empirically based account of similarities among relations for a wider range of relations than previous research had done.

\section{An A Priori Taxonomy of Semantic Relations}

Inspection of earlier classification schemes suggests the existence of five main families of relations: contrast, class inclusion, similars, case relations, and part-whole relations (Evens et al., 1980; Flavell \& Flavell, 1959; Miller, 1969; Perfetti, 1967; Riegel \& Riegel, 1963; Whitehurst, 1979; Woodworth, 1938; Wundt, 1893). The agreement on these five families is not unanimous; for example, some classification schemes group class inclusion with part-whole relations (e.g., Trautscholdt, in Warren, 1921, p. 248), whereas others do not (e.g., Aschoffenburg, in Warren, 1921, p. 249; Kraepelin, in Warren, 1921, p. 250). These five families, nevertheless, provide an a priori framework within which the relations selected for the study will be described. The relations selected include most of the relations mentioned in earlier classification schemes, together with others found in the work of linguists and philosophers. In addition, we distinguished several types of part-whole relation.

Contrast. This family consists of relations in which the meaning of one term contrasts, opposes, or contradicts the other term (Bolinger \& Sears, 1981; Cruse, 1976; Groves, 1973; Kempsen, 1977; Leech, 1974; Lyons, 1968; Ogden, 1932). This class includes four types of antonym relation and three types of relations involving opposition that is not generally regarded as antonymous. Contradictory antonyms are terms op- posed dichotomously (e.g., "alive-dead"). Contrary antonyms are opposed symmetrically on a continuous dimension (e.g., "hot-cold" are equally opposed temperatures). Directional antonyms are concepts opposed in time or space (e.g., "before-after," "above-below"). Reverse antonyms, sometimes called converses, represent opposed actions (e.g., "buy-sell"). Of the relations not normally regarded as antonymous, asymmetric contraries are opposed on a continuous dimension but, as the term indicates, asymmetrically (e.g., "hot-cool"); the imperfect symmetry is the reason the relationship is not generally regarded as antonymic (Katz, 1972). Incompatibles are terms in which the denotative meaning of one term is opposed to only part of the denotative meaning of the other term; for example, "frank" is incompatible with "hypocritical" in that hypocrisy involves dishonesty, whereas frankness involves both honesty and outspokenness. Because the opposition does not involve the full denotative meaning of these terms, they are not antonyms (Groves, 1973). Pseudoantonyms are so called because their opposition is based on a connotative meaning of one term; for example, "popular" and "shy" are opposed because popularity connotes extroversion, which is denotatively opposed to shyness (Herrmann et al., 1979).

Similars. This family consists of terms that overlap in denotative meaning, connotative meaning, or both. The best known of these relations is synonymity, in which terms have the same denotation (e.g., "car-auto"; Herrmann, 1978; Naess, 1953). Dimensional similarity involves denotative agreement that is not sufficient for synonymity but that occurs at adjacent points on a common dimension (e.g., "laugh-smile"; Flavell \& Flavell, 1959). Another relation in this family is attribute similarity, in which salient attributes of one term resemble those of another (e.g., "rake-fork"; Perfetti, 1967). The above similarity relations require terms to be in the same form class. Necessary attribution, in contrast, involves a term and a defining attribute of the term (e.g., "lemon-sour"; Flavell \& Flavell, 1959).

Class inclusion. Relations in this family involve one term whose denotative meaning subsumes that of the other term. Unlike the other relation families, there are no precedents or clear logical grounds for distinguishing different types of class inclusion relations. Nevertheless, six types were included in the present study so that the class inclusion relation should be as well represented as the other major relations. We distinguished the six types through the kind of information that forms the basis for the inclusion relation. Perceptual subordinates are objects that are principally characterized by their visible, physical properties (e.g., "animal-horse"; see E. V. Clark, 1973, and Rosch \& Mervis, 1975). Functional subordinates are objects that are principally characterized by their functions (e.g., "vehicle-car"; see Nelson, 1974). State subordinates and geographical subordinates involve, respectively, states (e.g., "emotion-fear") and places ("country-Russia"). Activity subordinates and 
action subordinates involve activities (e.g., "gamechess") and actions ("cook-fry"), respectively.

Case relations. The relations involved in predication or attribution have been variously described as case, syntactic, and syntagmatic relations (Fillmore, 1968; Flavell \& Flavell, 1959; Warren, 1921). These relations have played a central role in network models of propositional knowledge (e.g., Anderson, 1976; Norman \& Rumelhart, 1975), in which the assignment of default values to cases of verbs has provided a powerful tool for explaining inferences (Rumelhart \& Ortony, 1977). For example, a typical agent for the activity of barking is a dog; the agent-action relation is exemplified by pairs such as "dog-bark." Often, agents have instruments that they typically use; "farmer-tractor" is an example of the agent-instrument relationship. Likewise, there are often typical objects of an agent's activity; "plumberpipes" is an example of the agent-object relation. A typical recipient of sweeping is the floor; the action-recipient relation is represented by pairs such as "sweep-floor." The action-instrument relation is represented by, for example, "cut-knife."

Part-wholes. The relations in this family involve inclusion that is pragmatic rather than necessary, as is the case with class inclusion (Chaffin, Herrmann, \& Andrews, 1981; Winston \& Chaffin, 1982). The relations selected were derived freely from the literature on the partwhole relation (Chaffin, Winston, \& Herrmann, 1984; Cruse, 1979; Goodman, 1951; Jespersen, 1933; Lyons, 1977; Markman \& Seibert, 1976; Miller \& JohnsonLaird, 1976; Nagel, 1961; Scharvy, 1980). Parts of functional ubjects are distinguished by the fact that they must be in a particular spatial and functional configuration in order to play their proper roles in the functioning of the whole (e.g., "airplane-wing"). Parts of functional loca. tions, in contrast, are less restricted in the spatial relaions they can have to other parts of the whole (e.g., "kitchen-refrigerator"). Spatial inclusion is also a characteristic of places and their parts, but in this case the inclusion is criterial and the function of the parts is irrelevant to the relation (e.g., "Germany-Hamburg"). For organizations, spatial inclusion is irrelevant; parts are related to the whole by their organizational status and by their function (e.g., "college-admissions office").

The preceding part-whole relations involve wholes that have heterogeneous parts. Two other part-whole relations involve parts that are homogeneous. Items in a collection are all similar to each other and are part of the whole merely by virtue of being close to one another (e.g., "tree-forest"; Markman \& Siebert, 1976). Groups are similar to collections of objects, except that members of groups are animate and the criteria for membership involve a social transaction rather than mere spatial proximity (e.g., "faculty-professor"). Two additional part-whole relations differ from the others in that their parts are not readily distinguishable or separable from one another. Ingredients cannot be separated readily from the whole (e.g., "pizza-cheese"; Scharvy, 1980), and units of measure (e.g., "mile-foot") also merge one with another.

\section{An Empirical Taxonomy}

An empirical taxonomy was developed by asking subjects to sort examples of the 31 relations described above. A hierarchical clustering analysis of the results yielded a taxonomy that summarized the subjects' classifications. If subjects perceive relations as falling into the five a priori families, these groupings will appear in the empirical taxonomy. It is possible that the empirical may differ from the a priori classification. Differences may occur, first, because the relations exhibited by a word pair are often ambiguous. For example, we selected "rug-blanket" and "rake-fork" to represent the relation of attribute similarity. The relation of "rugblanket" might also, however, be viewed as class inclusion, if a blanket is viewed as a type of rug, or as coordination, if rugs and blankets are both viewed as types of covering. To minimize this kind of misinterpretation, five examples of each relation were used. Second, a relation may have properties of more than one family. For example, attribute similarity might legitimately be regarded as a similarity relation or as a contrast relation, such as "pepper-salt." Third, the families identified in the a priori analysis may not represent the most natural grouping of the relations selected. For example, subjects may not distinguish part-whole from class inclusion or class inclusion from similarity; similarity might be viewed as a type of case relation or as akin to contrast.

\section{METHOD}

\section{Subjects}

Forty undergraduate students of Hamilton College per formed a sorting task and were paid $\$ 1.00$ for each $.5 \mathrm{~h}$ served

\section{Procedure}

Thirty-one relations were selected for the sorting task, with five examples representing each relation. The five example: for each relation were typed on $3 \times 5$ in. cards, with each rela tion being represented by one card. The 31 relations and the examples used for each are listed in the Appendix.

The subjects were given the deck of 31 cards and instructec to sort the cards into two or more piles such that cards repre senting the same or similar relations were in the same pile. The task was illustrated with two additional relations: coordinate: ("doctor-lawyer") and reciprocals ("judge-defendant").

\section{RESULTS}

The sorting data were first summarized in a $31 \times 31$ similarity matrix that represented the number of sub jects who placed each pair of cards in the same pile The upper and lower halves were then collapsed anc analyzed by a hierarchical clustering procedure (diamete: method; Johnson, 1967). The solution is shown ir Figure 1; clusters based on 13 or more subjects wert significant $(p<.05 ;$ Fillenbaum \& Rapoport, 1971). The 


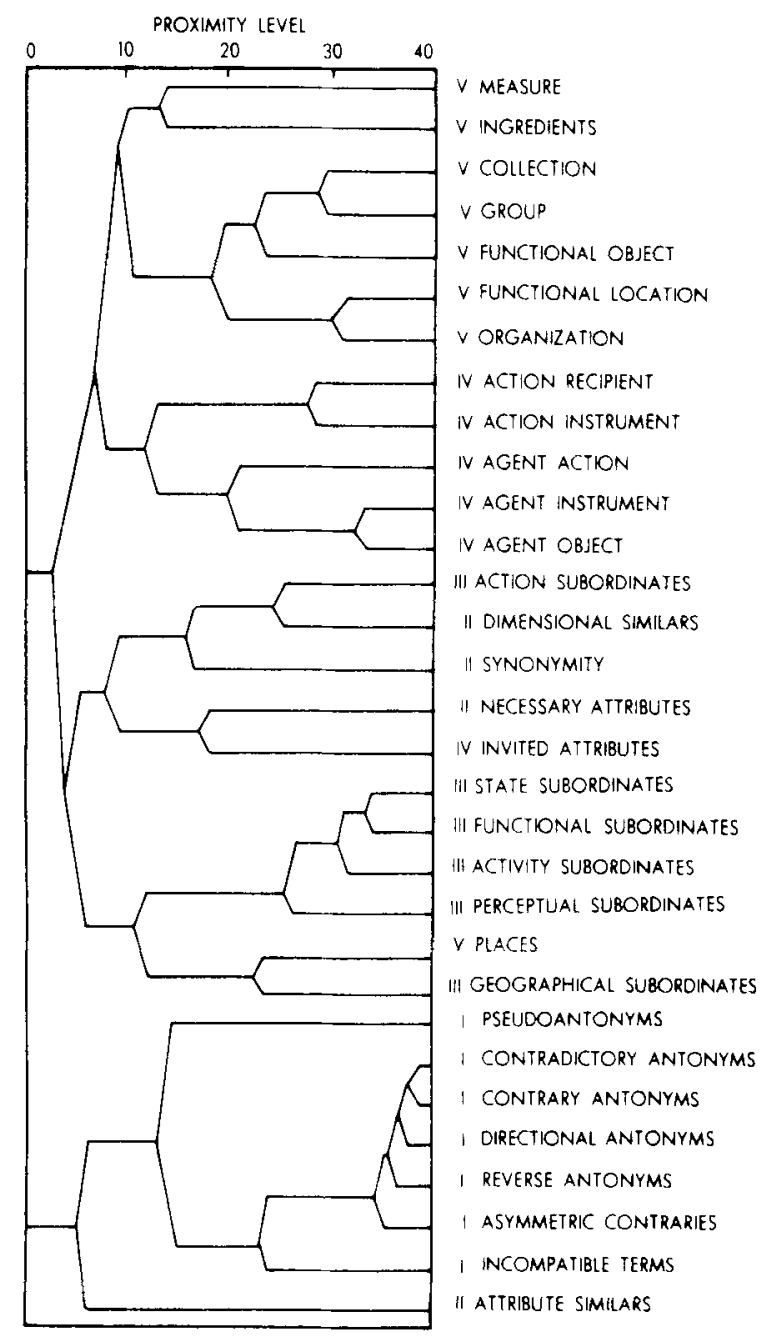

Figure 1. Hierarchical clustering solution for 31 semantic relationships.

fit of the solution to the data was assessed by correlating similarity matrices for the solution and the data; the fit was satisfactory $[\mathrm{r}(463)=.75, \mathrm{p}<.001]$.

Inspection of Figure 1 shows that the most general distinction recognized by the subjects was that between contrasting and noncontrasting relations. The noncontrasting relations, in tum, were divided into two kinds: logical relations (the left branch) and pragmatic relations (the right branch). These were, in turn, each composed of two of the a priori groups. The logical relationssimilar and class inclusion relations-involve an overlap in the meaning of the two terms in a relation and thus are based on similarity. The pragmatic relations-partwhole and case relations-do not involve similarity of meaning; rather, the two concepts are related by a pragmatic association. The two families of inclusion relations-part-whole and class inclusion -were located in separate branches of the taxonomy. The property of inclusion thus distinguished the two families of logical and the two families of pragmatic relations. The five families were thus distinguished in terms of the three properties: contrasting/noncontrasting, logical/pragmatic, and inclusion/noninclusion.

The five main groups of relations in Figure 1 correspond to the five a priori groupings. This can be seen by inspection of the Roman numerals representing the a priori classification of each relation in Figure 1. There were four instances in which relations were placed in groups that differed from their a priori classifications. Three of these were reasonable alternative classifications; one was based on a superficial similarity of content. First, the relation of invited attributes ("stove-hot") was grouped with similars rather than with the case relations. Within the family of similarity relations, invited attributes were sorted most frequently with necessary attributes ("tower-tall"), indicating that the subjects saw invited and necessary attribution as having relation properties in common. Second, action subordinates ("cook-fry") were also included with the similars rather than with the class inclusion relations; again, this was not an error on the part of the subjects, since action subordinates and superordinates are often used interchangeably, which is a feature of synonymity but not of class inclusion. Third, attribute similars ("rake-fork") were placed with the contrast relations. This is perhaps more appropriate than the a priori grouping with the similars; attribute similars are coordinates, which is a contrast relation (Chaffin \& Herrmann, 1981). The only disagreement with the a priori classification that cannot be explained in terms of defining properties of the relations was the sorting of the partwhole relation for places ("Germany-Hamburg") with the class inclusion relations. This unexpected result appears to have been due to the subjects' confusing the part-whole relation of geographic inclusion with the class inclusion relation for geographic terms ("countryRussia").

Relations within each family were also organized by similarity. Among the part-whole relations, the major distinction was between those relations involving parts that can be readily distinguished from each other, for example, integral object-proper part ("car-engine"), and the relations involving indistinguishable parts, for example, measure-unit ("mile-yard"). Case relations were divided into relations involving agents and those involving actions. Relations in the similars cluster were organized by the type of concept involved: actions, objects, or properties. The main division of class inclusion relations was between places and the other concepts, which were, in turn, divided into classes for which the membership criteria were perceptual, that is, perceptual subordinates ("tree-oak"), and classes for which the criteria were abstract, that is, states ("illness-measles"). The contrast relations were sorted in terms of degree of approximation to the antonym relation. The four relations that are generally regarded as antonyms, for example, contraries ("hot-cold"), were clustered 
most closely, and the least antonymic relations, pseudoantonyms ("popular-shy") and attribute similars ("rakefork") were sorted with these least often.

\section{DISCUSSION}

The taxonomy in Figure 1 replicates many aspects of Wundt's (1893) classification scheme and the schemes of several others (Warren, 1921). First, as expected, there were five major branches in the solution, corresponding to the five families of relations that have appeared in many earlier classifications (Warren, 1921; Whitehurst, 1979). Second, the organization of the five families coincides with earlier semantic analyses of relations. The contrasting/noncontrasting distinction, used here to describe the highest level division of the five families, has been made by some philosophers (Kempson, 1977). Also, the logical/pragmatic distinction evident in the present data was strongly anticipated by prior schemes that classified relations on the basis of internal and external associations (Warren, 1921; Wundt, 1893). The two inclusion relations were distinguished (Markman \& Seibert, 1976); class inclusion was placed with the logical relations, part-whole with the pragmatic relations.

The subjects were able to follow instructions to sort by relation similarity and did not use other criteria. Subjects did not sort in terms of the semantic similarity of the examples; for example, functional locations ("kitchen-refrigerator") and types of artifact ("kitchen utensil-spatula") were correctly placed in different families. [Only in the case of geographic inclusion ("GermanyHamburg") did the subjects sort by semantic similarity.] The subjects also did not sort on the basis of form class; for example, relations exemplified by noun-noun pairs were correctly assigned to each of the major clusters: "car-engine" to part-whole, "farmer-tractor" to case relations, "car-auto" to similars, "vehicle-car" to class inclusion, and "rake-fork" to contrasts. The subjects also did not use strength of association as a criterion; in each family, there were some relations illustrated by strong and some by weak associations; for example, "alivedead" and "popular-shy" were both classified as contrast relations. The subjects' ability to avoid using these alternative bases for classification indicates that they were able to identify relations from the examples and to compare them in terms of the properties that defined the relations.

In addition to providing a taxonomy and a similarity metric for semantic relations, the present results make two general points about semantic relations that have implications for models of semantic memory and models of semantic decisions. First, the study makes the point that there are more distinct semantic relations than those discussed in recent work. Current models of semantic memory that represent propositional knowledge (e.g., Anderson, 1976; Norman \& Rumelhart, 1975; Schank, 1973) have limited the number of relations that they encompass in the interests of parsimony.
The power and scope of these models would be increased by incorporating the variety of relations used in the present study. This is because each relation has its own properties and therefore supports different inferences.

How many relations must be accounted for is unclear. It is clear that the types of relation will not suffer the indefinite proliferation that was thought to afflict semantic features (Bolinger, 1965). There are fewer relations than there are pairwise associations between words; word pairs that clearly share the same semantic relation were easily identified in the present study. Even if the number of relations proves to be large, the task of accounting for their diversity is made more manageable by the organization of relations into families. There may, of course, be families of relations not identified here, but it is unlikely that their number will be large, since the relations used in this study were based on an extensive search of the literature. The suggestion that models of semantic memory should encompass the diversity of relations is not, therefore, an unreasonable one.

The second point that the present data make is that relations need not always be treated as unanalyzable primitives. The subjects were able to group relations in terms of relation similarity. This required a discrimination of aspects in which relations were the same and different (cf. Tversky, 1977). Those aspects of the relations that subjects distinguished most frequently are represented by the major branches of the taxonomy: contrasting/noncontrasting, logical/pragmatic, and inclu. sion/noninclusion. Within each family, further distinc. tions were made; within the part-whole family, for example, the subjects discriminated relations with dis. tinguishable and indistinguishable parts. These distinc. tions represent the semantic and logical properties that define relations (Kempsen, 1977; Leech, 1974; Lyons $1968,1977)$. Each family is characterized by relatior properties common to all members; the members of the family each possess additional relation properties that determine the way in which the common relatior properties are expressed. For example, among the contrast relations, contrary antonyms ("hot-cold". are opposed on a continuous dimension, whereas contra dictory antonyms ("alive-dead") are opposed on : dichotomous dimension.

The subjects in the present experiment were able tc decompose relations into their component properties This suggests that relation properties may play a role ir other cognitive tasks involving semantic relations. (Wt have suggested elsewhere that antonym decisions involvt an evaluation of properties that define the antonym rela tion; Herrmann, Chaffin, \& Daniel, 1984; Hermann e al., 1981.) The present data do not indicate how de composition is accomplished. Some relational knowledg is almost certainly computed, for example, that tomato is more readily squashed than a cabbage, whereas other knowledge is almost certainly prestored for example, that people have thumbs (Smith, 1977) 
Decomposition of prestored relations is readily explained if relations are stored as bundles of links, each link representing a property of a relation. If prestored relations are represented as atomic and unanalyzable links, some additional computation is required to account for decomposition.

In summary, a rich diversity of relations exists in natural language. We suggest that models of semantic memory would be enhanced by encompassing this diversity. The problems of representing a large number of distinct relations in semantic memory are made manageable by the fact that relations can be decomposed into defining properties that are shared in varying numbers by different relations. The ability of the subjects in the present experiment to do this suggests that a similar process of decomposition may operate in other situations that require the comprehension of relations.

\section{REFERENCES}

Andenson, J. R. (1976). Language, memory, and thought. Hillsdale, NJ: Erlbaum.

Bienwisch, M. (1970). Semantics. In J. Lyons (Ed.), New Horizons in linguistics. Harmondsworth, England: Pelican Books.

Bolinger, D. L. (1965). The atomization of meaning. Language, 41, 555-573.

Bolinger, D., \& Sears, D. A. (1981). Aspects of language (3rd ed.). New York: Harcourt Brace Jovanovich.

Chaffin, R., \& Herrmann, D. J. (1981). Semantic relationships and the generality of semantic-memory models. Bulletin of the Psychonomic Society, 17, 69-72.

Chaftin, R., Herrmann, D. J., \& Andrews, K. (1981, April). Effects of relationship similarity on the latency of part-whole decisions. Paper presented at the meeting of the Eastern Psychological Association, New York.

Chafrin, R., Russo, A., \& Herrmann, D. J. (1981). An effect of relationship similarity on categorization latency. Journal of General Psychology, 104, 293-302.

Chaptin, R., Williamg, P., Herruane, D. J. (1982, April). Similarity effects in the part-whole decision task. Paper presented at the meeting of the Eastern Psychological Association, Baltimore.

Chaftin, R., Wineton, M., \& Hernuann, P. J. (1984). The semantics of part-whole relations: An empirical taxonomy. Manuscript submitted for publication.

Clark, E. V. (1973). What's in a word? On the child's acquisition of semantics in his first language. In T. E. Moore (Ed.), Cognitive development and the acquisition of language. New York: Academic Press.

Clark, H. H. (1970). Word associations and linguistic theory. In J. Lyons (Ed.), New horizons in linguistics. Baltimore: Penguin Books.

Cohen, G. (1977). The psychology of cognition. New York: Academic Press.

Collins, A. M., \& Quillian, M. R. (1969). Retrieval time from semantic memory. Journal of Verbal Learning and Verbal Behavior, 8, 240-248.

Chuse, D. A. (1976). Three classes of antonym in English. Lingua, 38, 281-292.

Cruse, D. A. (1979). On the transitivity of the part-whole relation. Journal of Linguistics, 15, 29-38.

Dank8, J. H., \& Gluckseeng, S. (1980). Experimental psycholinguistics. In M. P. Rosenweig \& L. W. Porter (Eds.), Annual review of psychology (Vol. 30). Palo Alto, CA: Annual Review.

Evanechxo, P. O., \& Maguire, T. O. (1972). The dimensions of children's meaning space. American Educational Research Journal, 9, 507-522.

Evens, M. W., Litowitz, B. E., Markowitz, J. A., Smith, R. N., \& Werner, O. (1980). Lexical-semantic relations: $A$ comparative survey (Current Inquiry into Language and Linguistics No. 34). Carbondale, IL, and Edmonton, Ontario, Canada: Linguistic Research, Inc.

Fillenbaum, S., \& RAPOPORT, A. (1971). Structures in the subjective lexicon. New York: Academic Press.

Fillmore, C. J. (1968). The case for case. In E. Bach \& R. T. Harms (Eds.), Universals of linguistic theory. New York: Holt, Rinehart \& Winston.

Flavell, J. H., \& Flavell, E. R. (1959). One determinant of judged semantic and associative connection between words. Journal of Experimental Psychology, 58, 159-165.

Glass, A. L., Holyonk, K. J., \& Kigen, J. I. (1979). Role of antonymy relations in semantic judgments. Journal of Experimental Psychology: Human Learning and Memory, 5, 598-606.

Goodman, N. (1951). The structure of appearance. Cambridge, MA: Harvard University Press.

Groves, P. B. (Ed.) (1973). Webster's new dictionary of synonyms. Springfield, MA: Merriam.

Herrmann, D. J. (1978). An old problem for the new psychosemantics: Synonymity. Psychological Bulletin, 85, 490-512.

Herrmann, D. J., Chaffin, R. J. S., Conti, G., Peters, D., \& Robrins, P. H. (1979). Comprehension of antonymy and the generality of categorization models. Journal of Experimental Psychology: Human Learning and Memory, 5, 585-597.

Herrmann, D. J., Chaffin, R., \& Daniel, M. P. (1984). The definition of antonymy and antonym comprehension. Manuscript submitted for publication.

Herrmann, D. J., Chaffin, R., Daniel, M. B., \& Russo, A. (1981, April). Properties of antonyms and the comprehension of antonymy. Paper presented at the meeting of the Bastern Psychological Association, New York.

JESPE RBEN, O. (1933). Essentials of English grammar. London: Allen \& Unwin.

Johnson, S. C. (1967). Hierarchical clustering schemes. Psychometrika, 32, 241-254.

KATz, J. J. (1972). Semantic theory. New York: Harper \& Row.

Kemp8en, R. M. (1977). Semantic theory. Cambridge: Cambridge University Press.

KinTsCh, J. (1980). Semantic memory: A tutorial. In R. S. Nickerson (Ed.), Attention and performance VIII. Hillsdale, NJ: Erlbaum.

Leech, G. (1974). Semantics. Middlesex, England: Penguin Books.

Lortus, E. F. (1973). Category dominance, instance dominance, and categorization time. Journal of Experimental Psychology, 97, 70-74.

LoRCH, R. F., Jn. (1981). Effects of relation strength and semantic overlap on retrieval and comparison processes during sentence verification. Journal of Verbal Learning and Verbal Behavior, 20, 593-610.

Lyons, J. (1968). Introduction to theoretical linguistics. Cambridge: Cambridge University Press.

Lyons, J. (1977). Semantics. Cambridge: Cambridge University Press.

Markman, E. M., \& Seibert, J. (1976). Classes and collections: Internal organization and resulting holistic properties. Cognitive Psychology, 8, 561-577.

McCloskey, M., \& Glucrseerg, S. (1979). Decision processes in verifying category membership statements: Implications for models of semantic memory. Cognitive Psychology, 11, 1-37.

MiLLeR, G. A. (1969). The organization of lexical memory: Are word associations sufficient? In G. A. Talland \&. C. Waugh (Eds.), The pathology of memory. New York: Academic Press. Miller, G. A., \& Johnson-Laird, P. N. (1976). Language and perception. Cambridge, MA: Harvard University Press.

NAEss, A. (1953). Interpretation and preciseness: A contribution to the theory of communication. Oslo: Jacob Dybwad.

NAGEL, N. (1961). The structure of science. New York: Harcourt, Brace \& World. 
NELson, K. (1974). Concept, word and sentence: Interrelations in acquisition and development. Psychological Review, 81, 267-285.

Norman, D. A., \& Rumelyart, D. E. (1975). Explorations in cognition. San Francisco: Freeman.

Ogden, C. K. (1932). Opposition. Bloomington: Indiana University Press.

Osgood, C. E., \& Richands, M. M. (1973). From yang and yin to and or but. Language, $49,380-412$.

Palermo, D. S. (1978). Psychology of language. Glenview, IL: Scott, Foresman.

Perfetri, C. A. (1967). A study of denotative similarity with restricted word associations. Journal of Verbal Learning and Verbal Behavior, 6, 788-795.

Riegel, K. F., \& Riegel, R. M. (1963). An investigation into denotative aspects of word meaning. Language and Speech, 6, 5-21.

Rosch, E., \& Mervis, C. B. (1975). Family resemblances: Studies in the internal structure of categories. Cognitive Psychology, 104, 192-233.

Rumelhart, D. E., \& Ortony, A. (1977). The representation of knowledge in memory. In R. C. Anderson, R. J. Spiro, \& W. E. Montague (Eds.), Schooling and the acquisition of knowledge. Hillsdale, NJ: Erlbaum.

SchaNK, R. C. (1973). Identification of conceptualization underlying natural language. In R. C. Schank \& K. M. Colby (Eds.), Computer models of thought and language. San Francisco: Frecman.

Scharvy, R. (1980). A more general theory of definite descriptions. Philosophical Review, 89, 607-624.

Smith, E. E. (1977). Theories of semantic memory. In W. K. Estes (Ed.), Handbook of learning and cognitive processes (Vol. 5). Hillsdale, NJ: Erlbaum.

Smith, E. E., Shoben, E. J., \& Rips, L. J. (1974). Structure and process in semantic memory: A featural model for semantic decisions. Psychological Review, 81, 214-241.

Tversky, A. (1977). Features of similarity. Psychological Review, 84, 327.352

WARREN, H. C. (1921). A history of the association psychology. New York: Scribner's.

Whitehurst, G. J. (1979). Meaning and semantics. In G. J. Whitehurst \& B. J. Zimmerman (Eds.), The functions of language and cognition. New York: Academic Press.

Winston, M., \& Chaffin, R. (August 1982). The semantics of part-whole relationships. Paper presented at the meeting of the American Psychological Association, Washington.

Woonworth, R. S. (1983). Experimental psychology. New York: Holt.

Wundr, W. (1893). Grundziige der physiologischen Psychologie. (Vols. 1-2, 4th ed.). Leipzig: Engelmann.

\section{NOTE}

1. We thank Mary Crawford for this example of a computed relation.

\section{APPENDIX}

Stimuli for Card Sort

I. Contrasts
A. Contradictory
male-female, alive-dead, remember-forget, fertile-sterile, guilty-innocent
B. Contrary old-young, thin-fat, smooth-rough, happy-sad, tall-short
C. Directional front-back, left-right, west-east, before-after, inside- outside
D. Reverse
attack-defend, buy-sell, love-hate, expand-contract, command-obey

E. Asymmetric Contrary fat-skinny, hot-cool, rich-destitute, dry-moist, large-tiny

F. Incompatible frank-hypocritical, vigilant-careless, happy-morbid, slow. stationary, healthy-inanimate

G. Pseudoantonym popular-shy, generous-poor, right-bad, believe-deny, push-stretch

II. Similars

A. Synonymity

car-auto, purchase-buy, die-expire, smart-intelligent, rapidly-quickly

B. Dimensional Similarity smile-laugh, hungry-starving, brutal-unkind, dirty-soiled torment-annoy

C. Attribute Similarity rake-fork, painting-movie, rug-blanket, valley-gutter, tower-needle

D. Necessary Attribution stripe-long, tower-high, bachelor-unmarried, giant-tall, hag-ugly

III. Class Inclusion

A. Perceptual animal-horse, flower-rose, metal-copper, fish-salmon, bird-robin

B. Functional musical instrument-violin, kitchen utensil-spatula, carpenters' tool-hammer, furniture-chair, vehicle-car

C. State disease-polio, emotion-fear, social status-blue collar, physical shape-healthy, marital status-divorced

D. Geographical city-Utica, country-Russia, continent-America, stateNew Jersey, planet-Mars

E. Activity sport-football, game-chess, crime-theft, arts-dancing, hobby-gardening

F. Action talk-lecture, clean-scrub, cook-fry, go-hurry, ask-beg

IV. Case Relationships

A. Agent Actions artist-paint, dog-bark, lion-roar, horse-gallop, oratorspeak

B. Agent Instrument farmer-tractor, soldier-gun, student-book, doctorstethoscope, janitor-mop

C. Agent Object carpenter-lumber, baker-bread, tailor-clothes, sculptorclay, plumber-pipes

D. Action Recipient sit-chair, hunt-prey, flush-toilet, eat-food, sweep-floor

E. Action Instrument drink-cup, cut-knife, write-pen, chew-teeth, wash-soap

F. Invited Attribution food-tasty, bed-comfortable, hospital-clean, lemon-sou professor-intelligent

V. Part-Wholes

A. Functional Object car-engine, tree-branch, house-roof, face-nose, airplanewing

B. Functional Location house-dining room, kitchen-refrigerator, library-card catalogue, campus-student union, store-cash register

C. Places Germany-Hamburg, Asia-China, New York City-Empirs State Building, Clinton-Town Square, Washington, D.C White House

D. Organization college-admissions office, a business-sales department, police force-homicide division, government-executive branch, army-supply corps 
E. Measure

mile-yard, pound-ounce, hour-minute, gallon-pint,

dollar-cent

F. Collection

forest-tree, fleet-ship, rockpile-rocks, range-mountain, bunch-grapes

G. Ingredients

ice cream-sugar, salad-tomato, pizza-cheese, shirt-cloth, table-wood
H. Group

choir-singer, regiment-soldier, faculty-professor, Senate-

Senator, orchestra-conductor

(Manuscript received June 30, 1983;

revision accepted for publication December 23,1983 .) 